\title{
Correction to: Web Information Systems Engineering - WISE 2020
}

\author{
Zhisheng Huang, Wouter Beek (D), Hua Wang (D), Rui Zhou (D, \\ and Yanchun Zhang (D)
}

\section{Correction to: \\ Z. Huang et al. (Eds.): Web Information Systems \\ Engineering - WISE 2020, LNCS 12342, https://doi.org/10.1007/978-3-030-62005-9}

In Chapter 12, the author's name was corrected to Deepak P.

In Chapter 24, a co-author listed on the Consent to Publish form was inadvertently forgotten. This mistake has been corrected and the forgotten co-author has been added.

The updated version of these chapters can be found at https://doi.org/10.1007/978-3-030-62005-9_12 https://doi.org/10.1007/978-3-030-62005-9_24 